\title{
Experimental left pneumonectomy in pigs: procedure and management
}

\author{
Antonello Bufalari, DVM, PhD, ${ }^{a}$ Valentina De Monte, DVM, PhD, ${ }^{a, 1}$ \\ Roberta Pecoriello, MD, ${ }^{b, 1}$ Livia Donati, DVM, ${ }^{a}$ Silvia Ceccarelli, MD, ${ }^{b}$ \\ Lucio Cagini, MD, ${ }^{b}$ Mark Ragusa, MD, PhD, ${ }^{b}$ and Jacopo Vannucci, MD $^{b \text {,* }}$

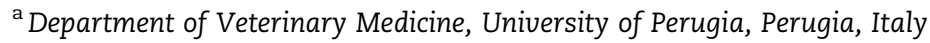 \\ ${ }^{\mathrm{b}}$ Department of Thoracic Surgery, Thoracic Surgery Unit, University of Perugia Medical School, Perugia, Italy
}

\section{A R T I C L E I N F O}

Article history:

Received 3 April 2015

Received in revised form

15 May 2015

Accepted 22 May 2015

Available online $\mathrm{xxx}$

\section{Keywords:}

Pneumonectomy

Surgery

Anesthesiology

Lung

Experimental

Animal model

\begin{abstract}
A B S T R A C T
Background: Because there is no detailed description of procedures and perioperative management of major pulmonary resections in swine, we reviewed our experience to delineate the most effective practice in performing left pneumonectomy.

Materials and methods: Analysis of 11 consecutive left pneumonectomies. Animal data, operative reports, anesthesia records, and perioperative facts were evaluated. Follow-up information until postoperative day 60 , methods of care-taking, therapy administration, and all the stabling aspects were systematically assessed. The investigation was aimed at highlighting those procedural steps or details which make the difference in optimizing the available resources (animals, instruments, and personnel). No statistical analysis was performed considering data characteristics and the descriptive nature of information.

Results: Surgery requires a median time of $2 \mathrm{~h}$ and $16 \mathrm{~min}$; two operators and one anesthesiologist represent the basic team. Circulators' number depends on goals to accomplish. The most straightforward procedure requires careful dissection of the pulmonary ligament (limited view), pulmonary veins (low variability), pulmonary artery (delicate), and finally bronchus (no variability observed). The key factors for good anesthesia management have been identified: sedation by caregivers, preoxygenation before induction of general anesthesia, high respiratory rates with low tidal volume after pneumonectomy, and noninvasive ventilation after extubation. Antibiotic prophylaxis has been performed. Postoperative care must be continuous until animals are able to stand up, afterward "preventive noncurative," and always animal friendly. Ideas for minimally stressful therapy administration are helpful.

Conclusions: After the delineation of this methodology, the compliance to a routine practice allowed us to reduce time, stress, and cost; quality and quantity of possible research increased.
\end{abstract}

(c) 2015 Elsevier Inc. All rights reserved.

\footnotetext{
* Corresponding author. Thoracic Surgery, University of Perugia Medical School, Loc. Sant'Andrea delle Fratte, Perugia 06134, Italy. Tel.: +39075 5782267; fax: +39075 5782600 .

E-mail address: jacopovannucci@tiscali.it (J. Vannucci).

1 These authors equally contributed. 0022-4804/\$ - see front matter @ 2015 Elsevier Inc. All rights reserved. 
1.

\section{Introduction}

Recent advances in animal laboratory have led to consistent evolution of experimental surgery research. Stricter regulations and attention to a model's reliability have assisted the improvement of research quality. Alongside this, there have been several developments in surgical models, whether for technical evolution in surgical procedures [1] or for functional research requiring a surgical operation [2]. Despite the progress of large animal models, some aspects still need to be clarified, especially concerning those models that are most commonly used, to give more space for comparison between different studies and a more straightforward execution of procedures. Among large models, pig, dog, and sheep are the preferred choices for surgical research but pig is becoming more and more attractive because of different characteristics (anatomy, previous knowledge, costs, necessary space, aggressiveness, sociality, and so forth). A very important additional factor to focus on the swine model is that the canine is no longer available in most European countries for regulatory changes.

A large number of investigations requiring pneumonectomy (PNCT) on animal model have been published but most of these articles just report that PNCT is performed, no details are often reported regarding pre-operative, intra-operative, and post-operative periods; thus, the operative phase of each research is carried out differently. This substantial lack was already denoted by Swindle [3] in his exceptional contribution regarding techniques and management of the swine model in which some information on how-to-do-it is given but it is still not sufficient to standardize the technique.

The aim of this study was, therefore, to outline the best routine to prepare, perform, and follow up a left PNCT in swine to give specific information so as to reduce operators' learning curve, surgical morbidity, animal stress, and investigator hesitation, as well as to extent comparability, to increase efficiency enhancing the focus on the main research and to assist the immediate procedure reproducibility for beginners.

\section{Materials and methods}

Left PNCT in female $35.81 \pm 6.44 \mathrm{~kg}$ swine is used in our Experimental Surgery Laboratory for different investigational purposes, and it is preferred over the contralateral because of the right tracheal bronchus, normally found in swine, and due to its inferior volume (right/left: 4/3) [4]. All the procedures were carried out in accordance with Local and Central Authorities for Animal Care and following the "Guide for the Care and Use of Laboratory Animals" (NIH publication, eight edition 1996).

Regardless of what the research objective was, we reviewed our preliminary experience on 11 models. Surgery reports and anesthesia records have been evaluated in each procedural category (techniques, instruments, timing, troubles, concerns, unexpected events, and variability). Animal behavior and reaction to manipulation were registered by caregivers and subsequently analyzed to assess the animal response to stabling, adaptation to environmental changes, feeding strategy, compliance to therapy administration, and follow-up observation during the standard period from preoperative day 7 to postoperative day 60 . The operating room layout, team members, and ordinary schedule (collegial meeting, routine organization, and operating room pacing) have been evaluated to assess the major issues, necessity of human and material resources, time managing, and preparation of second phase (research protocols).

Considering the descriptive variables, the data collection methodology, and the sample size, no statistical analysis was performed. The numeric records were analyzed by the properties of Microsoft Excel (Microsoft Corp, Redmond, WA).

\section{Results}

\subsection{Documental records}

Animals can be restless, potentially, for a period of a week after arrival; manipulation (physical examination and contact) could be a trigger for an aggressive reaction. Caregivers might report different findings if they are several and if collegiality is limited with daily staff turnover. More than three feeding rounds can cause the animal's attitude to fluctuate, which can lead to increasing difficulty for medical screening. Pigs look for water if it is not constantly available. Animals show friendly behavior to two constant caregivers (active approach instead of defense position).

Premedication effects before surgery are predictable if carried out by constant caregivers while it is less straightforward with possible stress if unknown researchers perform it. Stressful premedication led to troublesome induction of general anesthesia in three cases. Given that the intubation of swine is rather laborious and sometimes requires more time compared with other species, preoxygenation before the induction of general anesthesia has proved to play an important role in balancing the oxygenation safety margin in the case of prolonged apnea at the moment of induction of anesthesia.

Before PNCT, a moment of hypotension (mean arterial pressure $<60 \mathrm{~mm} \mathrm{Hg}$ ) in a pig was treated and solved by lowering the sevoflurane inhalation (2\%) and administering $10 \mu \mathrm{g} / \mathrm{kg} / \mathrm{min}$ of dobutamine for $20 \mathrm{~min}$. A pig with an otherwise straightforward anesthetic procedure was reintubated soon after the extubation because apnea and mild cyanosis were noted. After $10 \mathrm{~min}$ of spontaneous respiration with pure oxygen, the pig was extubated and noninvasive ventilation (NIV) was introduced. High respiratory rates (up to 50 breaths/ $\mathrm{min}$ ) and a low tidal volume (TV; $8 \mathrm{~mL} / \mathrm{kg}$ ) are required after the PNCT. NIV has been reported to be a valuable option to assist respiration soon after extubation. Despite myoresolution being continually achieved, we encountered muscle contraction at parietal level during electrocautery use.

Surgery was approached as it is for humans. Anatomic variability was minimal. We reported the absence of azygos (1) and right posterior pulmonary vein (PV) flowing into the left posterior PV (1). Mortality (1) and morbidity (3) were detailed. Morbidity was characterized by mild transient hemoptysis (36 h, bronchial stump bleeding), third week constant fever 
(39.0/39.8 $\mathrm{C}$, lamp overheating), and a case of pneumonia. Mortality was related to the left diaphragmatic hernia. Fever during the first week was not considered for complication analysis.

A postoperative course is more problematic if the animal delays standing up. When pigs stand up, cardiopulmonary balance is inevitably good. The presence of caregivers is fundamental until the animals stand up: supportive care (neck position, mouth cleaning, and self-damage prevention - two cases), therapy adjustment (pain service, diuretic, and antiemetics - four cases), and observation for possible reintubation. In all cases, after the pigs stood up, no medical support was necessary until the day after. The time taken for complications to develop allows caregivers the possibility to check on the animal every $12 \mathrm{~h}$. After postoperative day 7, the afternoon round did not offer any valuable additional information to the morning session. "Curative" follow-up is very expensive, with an increase in cost of over $100 \%$ if strict echographic follow-up is performed, additional therapy is carried out (pharmacologic or supportive) or re-do surgery is planned.

\subsection{Description of best practice}

Taking into consideration documental records, as well as the analysis of possible adverse events, key factors, and critical issues, the most efficient routine to follow is outlined.

\subsubsection{Preoperative management}

Pigs are transferred to the experimental center $1 \mathrm{wk}$ before the operation to minimize unexpected contingencies. Caregivers should avoid animal manipulation before surgery. A lateral chest x-ray is performed the day of the operation, just before the induction of general anesthesia. Observation in different phases of the day is carefully undertaken to inspect animal reaction to the stress of moving and to solitary condition. Appetite and level of attention must be considered; a complete health check up is crucial: problems such as cough or skin, muscle tone, digestive, and breathing disorders need to be ruled out. The impact of changes is a potential risk factor for the postoperative course. Strict routines in feeding, medical control, lights, temperature, and room sanitization help animal adaptation.

\subsubsection{Surgery}

The animal is put in right lateral decubitus position with a $3-\mathrm{cm}$ foam rubber under the chest to achieve a mild body convexity (Fig. 1A). The anterior leg is pulled cranially $\left(30^{\circ}\right)$. First surgeon at dorsal side, second surgeon at ventral side. The top of the thoracic curvature needs to be precisely at the level of the ideal thoracotomy line. Careful skin scrubbing is performed. The midpoint of the incision is found exactly in the mid longitudinal thoracic plane. Direction of thoracotomy goes from the first nipple to $2 \mathrm{~cm}$ below the tip of the scapula and then bends posterocranially around the scapula for no more than $5 \mathrm{~cm}$. Skin incision is $17 \pm 2 \mathrm{~cm}$. The most appropriate intercostal space to enter the chest is that which is completely uncovered by the tip of scapula (seventh intercostal space). Careful smooth pleural cavity opening is advised due to the very soft visceral pleura of swine. Careful pleural opening at the inferior site of the thoracotomy (pericardial contiguity) and the extent

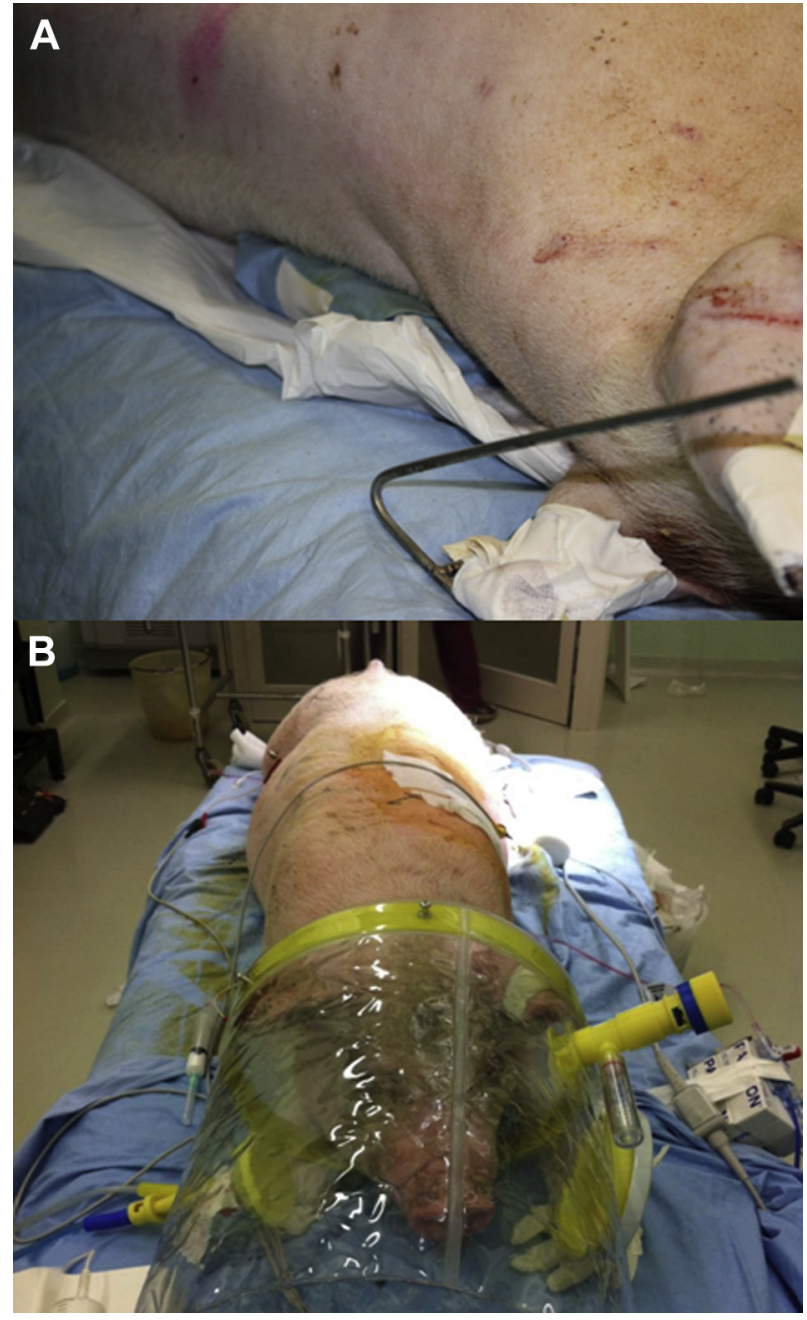

Fig. 1 - A soft wedge is placed under the chest to enhance the body convexity (A); it is of great help to widen the intercostal space and create a better exposure. After extubation, spontaneous breathing is supported by NIV in sternal position (B). (Color version of the figure is available online.)

of the posterior incision length (incision over the dorsal muscles) is essential to avoid imprecise surgery. Single ribs spreader (Finocchietto) is sufficient.

The first technical passage to accomplish is the dissection of the pulmonary ligament. This step could be difficult due to the limited view considering that the ligament suspends the posterior lung dorsally and might be very deep in the costdiaphragmatic space. The first surgeon lifts the caudal chest wall up to allow the second surgeon to dissect the ligament. Hemostasis might be complicated. Once the lung is completely free, hilum dissection starts with PV preparation. There are always two PVs: cranial and caudal (Fig. 2A). They represent the most superficial plane from the anterior view of the mediastinum. The cranial vein is much easier to dissect than the caudal; its extrapericardial course is always favorable for blunt dissection and hold on vessel loop. The caudal vein can be very deep in the parenchyma, which is very soft and easy to injure in pigs. Several passages from sternal to dorsal view and from below are necessary. After preparing the superior part of 

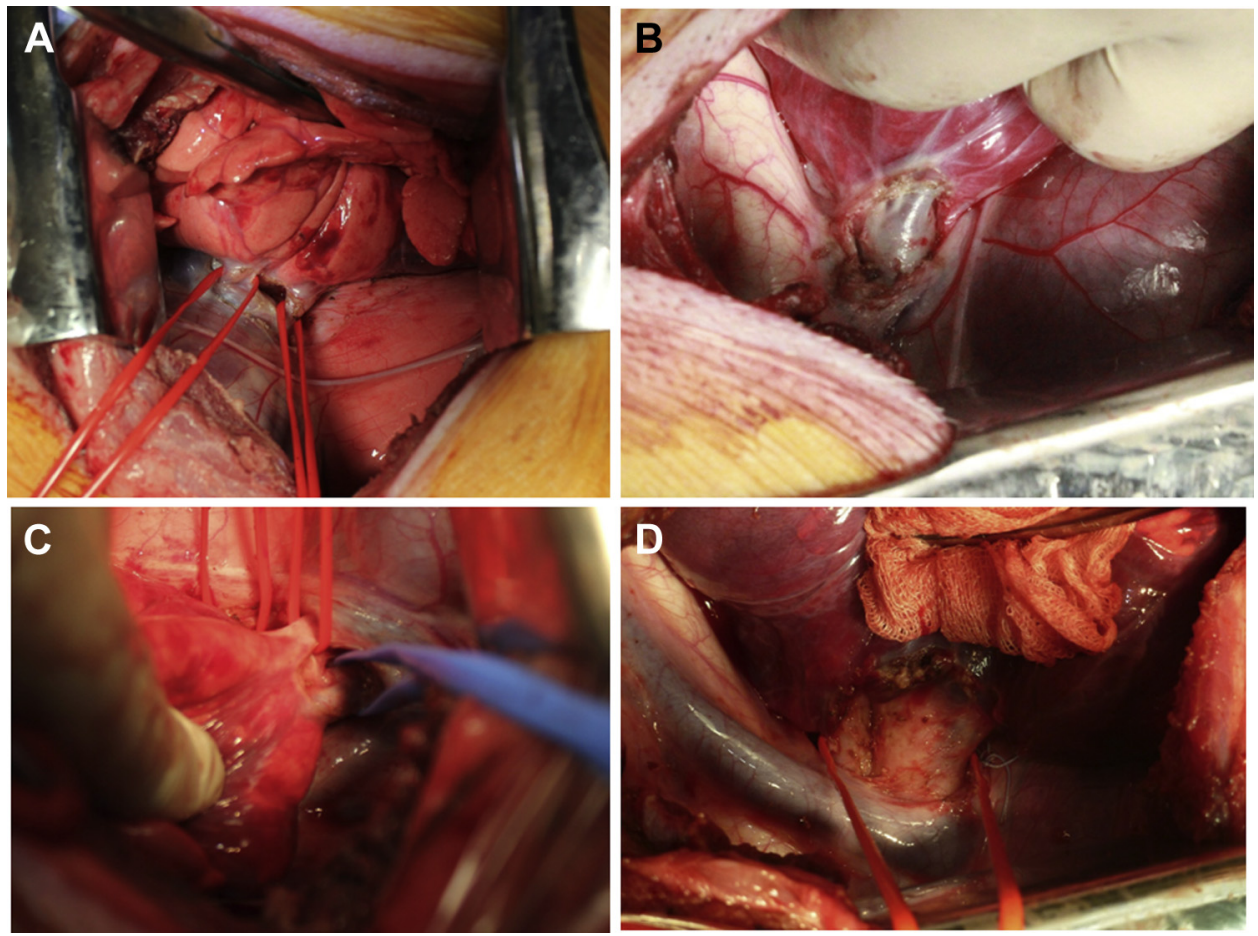

Fig. 2 - Anterior view of the mediastinum with pulmonary veins on red vessel loop (A); pulmonary artery is found at the top of the lung hilum (B); posterior view with pulmonary veins held on red vessel loop, and pulmonary artery held on blue vessel loop (C). Red vessel loop encircles the pulmonary artery (anterior) and the main bronchus (posterior) emerging below the azygos (D). (Color version of the figure is available online.)

the vein cranially, the dissection is carried out caudally. When both veins are held on vessel loop, the dissection of the main pulmonary artery (PA) begins. It is deep in the mediastinum and is found at the top of the hilum (Fig. 2B). It is in close proximity to several structures: posterior to the anterior PV, sometimes hidden by it, inferior to left azygos, and it lies on the main bronchus. Dissection from the azygos, subsequently from the PV (if still not satisfactory), and finally from the bronchus is the most efficient and time saving method. Once the hold on the vessel loop of PA is accomplished (Fig. 2C), the main bronchus dissection needs only completion (Fig. 2D, Video 1). The pulmonary artery requires an inframediastinal dissection of $1 \mathrm{~cm}$ to have the stumps protected by the mediastinum after PNCT (strongly suggested). After PNCT preparation, a sequence of sutures is carried out. Anterior then posterior PV (double ligation 2-0 unabsorbable, easier if performed by second operator), PA (mechanical $30 \mathrm{~V}$ or vascular clamp and 4-0 Prolene [Ethicon, Johnson \& Johnson company, Somerville, NJ] running suture), and bronchus (mechanical or bronchial clamp and 3-0 Vicryl [Ethicon, Johnson \& Johnson company, Somerville, NJ] interrupted suture).

Lavage, hydropneumatic test of the bronchial stump (underwater stump with progressive airway pressures) at 20, 30, and $40 \mathrm{~cm} \mathrm{H}_{2} \mathrm{O}$ is performed. Chest closure with no chest tube. The entire procedure requires $136 \pm 40 \mathrm{~min}$. The step-by-step description of the procedure is illustrated in Figs 3-6.

\subsubsection{Anesthesia}

Based on the estimated body weight, $6 \mathrm{mg} / \mathrm{kg}$ of tiletaminezolazepam and $0.2 \mathrm{mg} / \mathrm{kg}$ of methadone were administered intramuscularly (IM) for sedation. After approximately 5 min, both auricular veins were catheterized and $10 \mathrm{~min}$ of preoxygenation (flow-by; $5 \mathrm{~L} / \mathrm{min}$ ) was given by face-mask. Anesthesia was induced with $2-4 \mathrm{mg} / \mathrm{kg}$ of propofol intravenously (IV) and after tracheal intubation animals were connected to a rebreathing circuit. Anesthesia was maintained with sevoflurane $(2.5 \%-3 \%)$ in $\mathrm{O}_{2}(50-100 \mathrm{~mL} / \mathrm{kg} / \mathrm{min})$. Sufentanil and lactated Ringer solution were infused at a constant rate of $0.5-1 \mu \mathrm{g} / \mathrm{kg} / \mathrm{h}$ and $10 \mathrm{~mL} / \mathrm{kg} / \mathrm{h}$, respectively, during the entire anesthetic procedure. Muscular paralysis was induced by administration of vecuronium bromide $(0.1 \mathrm{mg} / \mathrm{kg}$, bolus IV) when necessary. Two $\mathrm{mg} / \mathrm{kg}$ carprofen was administered IM after intubation. Lungs were ventilated in a volume-controlled mode with a TV of $12 \mathrm{~mL} / \mathrm{kg}$, an inspiratory-to-expiratory time ratio of $1: 2$, a fraction of inspired oxygen of 1 , positive end expiration pressure of $3 \mathrm{~cm} \mathrm{H}_{2} \mathrm{O}$, and a peak airway pressure of $25 \mathrm{~cm} \mathrm{H}_{2} \mathrm{O}$; respiratory rate was regulated to maintain the endtidal carbon dioxide at $35-40 \mathrm{~mm} \mathrm{Hg}$. Pigs were positioned in right lateral recumbency on a heating pad.

After surgical exposure, a 20-gauge needle catheter was aseptically placed in the right femoral artery for the invasive measurement of arterial blood pressure and for arterial blood samples.

Physiological parameters were monitored and recorded every $5 \mathrm{~min}$. Just before opening the chest cavity, an intercostal block (1 mg/kg of bupivacaine $0.5 \%$ ) was performed including the level of thoracotomy and the two contiguous intercostal nerves.

After the PNCT, the TV was reduced to $8 \mathrm{~mL} / \mathrm{kg}$ and the respiratory rate $(R R)$ was regulated to maintain the end-tidal 


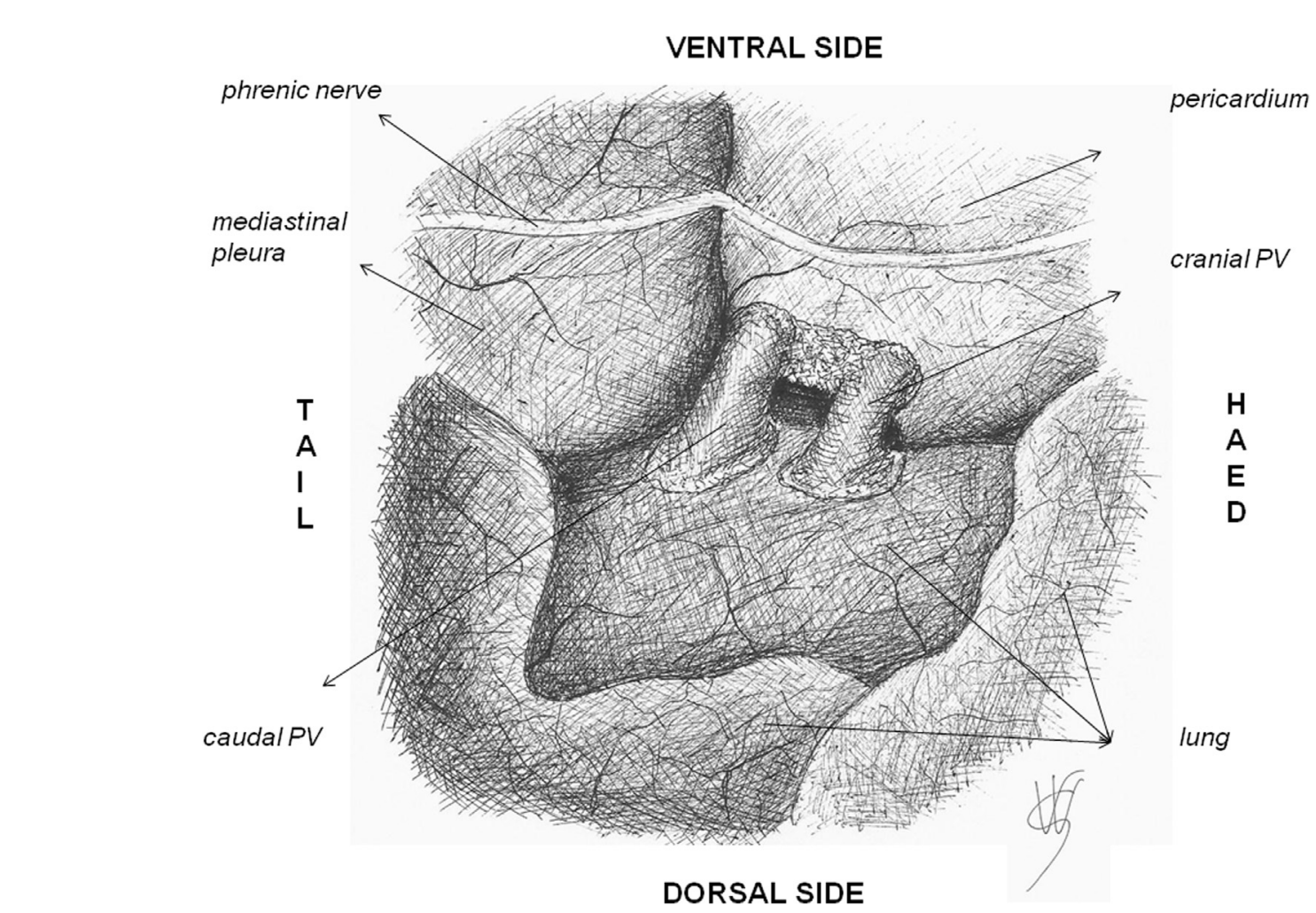

Fig. 3 - Pulmonary veins are exposed by pulling the lung toward the dorsal side. The cranial vein is dissected first; the caudal vein is subsequently approached. The phrenic nerve is seen. No need to open the pericardial sac to have a good preparation of pulmonary veins. Careful dissection is needed in proximity to mediastinal pleura, which is velamentous and frail.

carbon dioxide at $40 / 45 \mathrm{~mm} \mathrm{Hg}$. Once the chest cavity was closed, pigs were weaned off the mechanical ventilator and spontaneous breathing was allowed. At the end of surgery, sevoflurane and sufentanil administration were discontinued, animals were extubated when the swallowing reflex returned. Buprenorphine $(10 \mu \mathrm{g} / \mathrm{kg})$ was administered IM. Immediately after the extubation, NIV was set in each pig by means of a helmet (CaStar CPAP hood, large; StarMed, Crane House, Molly Millars Lane Wokingham, Berkshire, UK, Fig. 1B) [5]. The flow of $\mathrm{O}_{2}$ was set at $10 \mathrm{~L} / \mathrm{min}$ and a fraction of inspired oxygen of approximately 0.4 was obtained in the helmet; the continuous positive airway pressure was set to $5 \mathrm{~cm} \mathrm{H}_{2} \mathrm{O}$. Pigs were sedated with a continuous infusion of propofol (0.1-0.2 mg/ $\mathrm{kg} / \mathrm{min}$ ) to obtain a good helmet toleration. The NIV was allowed for $3 \mathrm{~h}$; after that time, propofol infusion was discontinued, the helmet was removed, and pigs were monitored by electrocardiogram and pulse oximetry to evaluate possible occurrence of arrhythmias or hypoxemia. After $30 \mathrm{~min}$, if no complication occurred, the animals were transferred to the stall and were continuously monitored for the following $12 \mathrm{~h}$.

\subsubsection{Postoperative follow-up}

The pig was transferred to single stall with absorbent litter, and caregivers stood near the animal until satisfactory return to equilibrium and a standing position was ascertained. Longlasting prostration in sternal recumbency is an alarming sign, in addition to breathing by mouth, which may suggest pain. Instruments for cardiopulmonary support need to be quickly available. No drink and food must be accessible until the morning after the operation. Medical therapy has several standpoints for animal safety and scientific methodology: complete certainty of what is given, homogenous administration among all models, minimal animal stress, and guarantee of a sustainable cost and/or effectiveness. To comply with these requirements, the follow-up must be "preventive noncurative."

All medications were administered IM with no exception. A broad spectrum antibiotic is given prophylactically for $5 \mathrm{~d}$ postoperatively. Ten microgram to kilogram of buprenorphine was administered every $12 \mathrm{~h}$ for $2 \mathrm{~d}$ and $2 \mathrm{mg} / \mathrm{kg}$ of carprofen was administered every $24 \mathrm{~h}$ for $5 \mathrm{~d}$.

The best technique to avoid animal stress involves the use

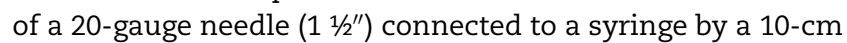
extension line. The needle is inserted at the cervical level and the solution is injected; after the entire volume is injected, a saline flush of catheter is performed. In this way, the pig can move and therapy is administered in all its posology with no animal restraint required.

A medical check is necessary twice a day and parameter monitoring is mandatory for $1 \mathrm{wk}$. After postoperative day 10 , the afternoon round could be avoided. Very important semeiologic reliability is related to fever and urination, secondarily appetite and general attention. Pigs with fever appearing after the first postoperative week (not due to operation impact) should be transferred to a different location and subintensively followed up. Immobility and food refusal are end-stage signs. Room temperature is crucial as swine homeostasis is delicate. The use of heating lamps is important but temperature should be set at $18^{\circ} \mathrm{C}-20^{\circ} \mathrm{C}$. Overheating with fever is recorded if lamp is $<180 \mathrm{~cm}$ and room temperature is not monitored. 


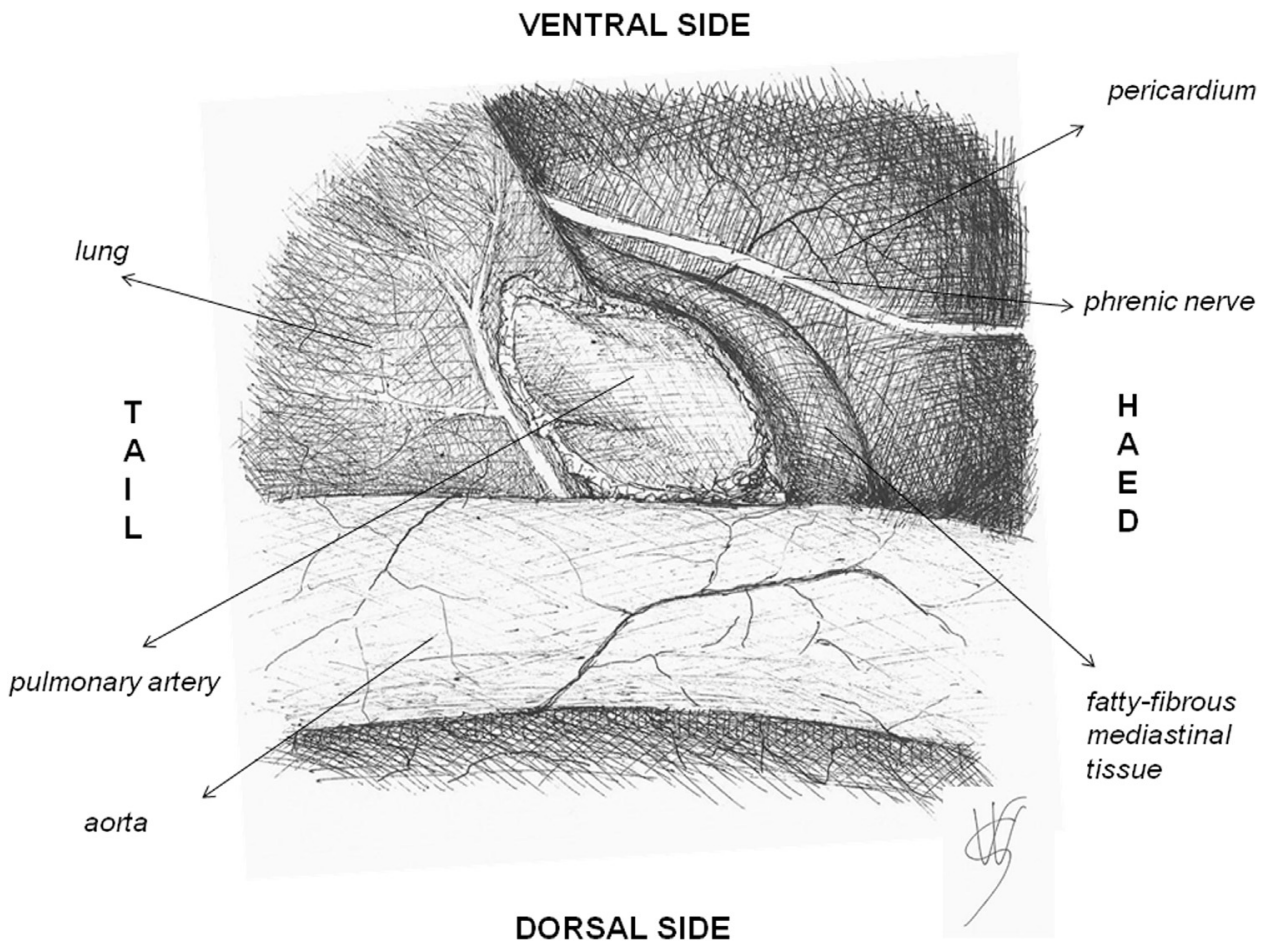

Fig. 4 - Pulmonary artery is approached at the top of hilum. It is found in the highest part of the mid-mediastinum between the aorta and upper pericardium. The dissection needs to take the proximity of the phrenic nerve into account. The achievement of the main pulmonary artery is hampered by the presence of the left azygos vein. Note that in this illustration the azygos vein is absent like in the pig represented in Figure $2 B$, so pulmonary artery dissection has been technically easier (compare Fig. 2B and D).

A postoperative course is well balanced if food is given twice a day, water is provided ad libitum, and if the stable is sanitized daily with a water wash and litter change. If personnel turnover is limited, animal stress and the referral of important information seem to be optimized.

\section{Discussion}

Experimental PNCT in the pig could create the biological condition to investigate different topics. The reduction of half of the respiratory field could be a surrogate of respiratory insufficiency [6] or it can create the condition to evaluate physiological changes after surgery $[7,8]$. Oncological investigations have been successfully performed for pleuropulmonary disease [9] as well as bronchovascular elements response to surgical stimulation [10,11]. Other potential fields of investigation are the supportive therapy for respiratory distress and perioperative medicine $[12,13]$. Swine PNCT could consequently represent the field for possible technical improvements or to test innovative solution considering the similitude to human body and the excellent adaptation of human surgery instruments. In biomedical research, the swine proved its role and it is described with some features of excellence to that the demand for this model is increasing. Regarding cardiorespiratory system, physiology and anatomy have already been described and compared with other species like the dog where the lung vascular system is less close to the human one. Moreover, the swine demonstrated a good outcome for safety and toxicology investigations [14].

Investigative surgeons currently couple the double task of exploring a research topic and after the experimental surgical procedure with its possible pitfalls, morbidity, and animal mortality. Detailed technical descriptions of procedures and experience reports have a crucial role in guiding others' practice through the concept of standardization, which is well-established in clinical medicine but still insufficient in experimental surgery. Some specific areas of investigation have already standardized surgical procedures for each specific model, so it is not infrequent to find articles referring to previous research about surgical procedure or results evaluation methodology [15].

The analysis showed that experience in human surgery is a good basis to perform experimental procedure in animal laboratories but surgeons may have some bias. The inferior third of a thoracotomy could expose the surgeon to possible damage of pericardium, which is often in close contiguity to the lateral bony chest; an overlong dorsal incision could easily be performed by surgeons with experience in human surgery where the costovertebral angle is less deep and acute. Swine left PNCT never requires left azygos dissection. Intrapericardial procedure is not suggested due to the especially anelastic pericardium and the very small swine heart [16]; a postpericardiotomy syndrome could easily be lethal. The dissection and/or section of each pulmonary vessel and finally the bronchus seem to be less efficient for the intraoperative course; the circulatory stability could be easily impaired in swine so it is preferable to 


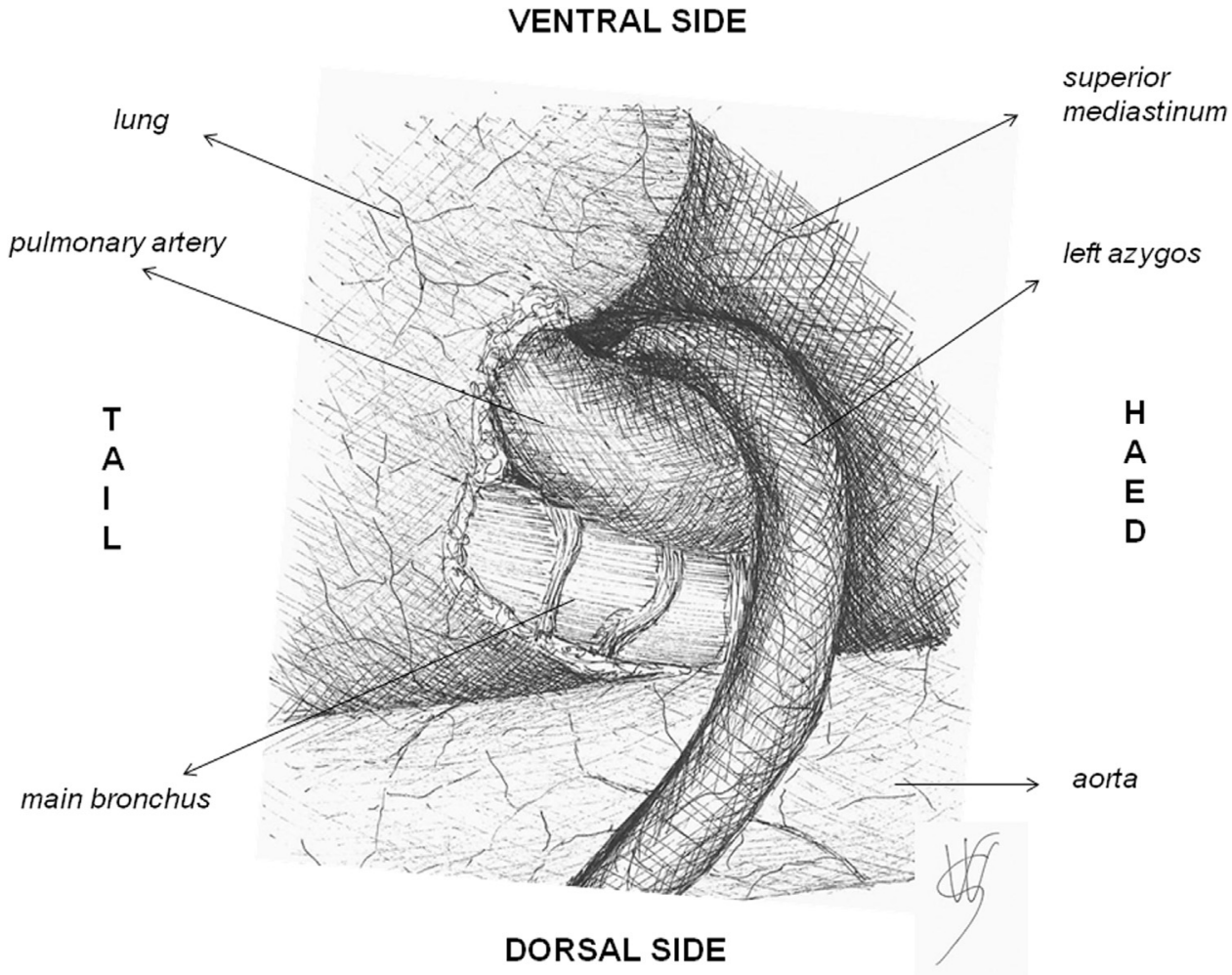

Fig. 5 - Bronchus is approached finally. Once pulmonary artery is held on vessel loop, the dissection of the main bronchus is almost achieved. It is performed by pulling the lung toward the ventral side.

dissect each PNCT component and then transect them. Swine lungs collapse very easily and PNCT can be performed with ventilating lungs with no apparent impact on operative time and surgical quality if mechanical ventilation is carried out after the aforementioned description; we have decided never to exclude the lung from ventilation to avoid disadvantages of one-lung ventilation [17].

The ligament could be minimal so the lung itself could represent the maximal part of such an anatomic structure; therefore, although the ligament is not well vascularized, the use of burning pick-ups is recommended. The possible connection between the ligament and the center of diaphragm makes diaphragm damage possible. This complication would be serious considering the very slight tendinous center.

Administration of sedative drugs by identified caregivers appears to induce better sedation in pigs; this event is desirable to prevent excitement during the animals' transfer to the surgical preparation room and anesthetic induction. It avoids an excess of sympathetic tone, which may cause cardiac arrhythmias up to ventricular fibrillation $[18,19]$.

Anesthesia for animals to be used for experimental PNCT requires qualified personnel with knowledge of ventilation and mechanical ventilators. After the PNCT, but during the ligation of pulmonary vessels, high respiratory rates (up to 50 breaths/min) are required to maintain normocapnia; furthermore, after the removal of the lung, the TV must be reduced in view of the one-lung ventilation [20-22].

Antiarrhythmic and vasoactive drugs must be readily available for use and their dosage should be precalculated.
At the end of the procedure, after extubation, everything necessary for reintubation (orotracheal tube, stylet, laryngoscope, and propofol) must be available.

In our experimental model, we applied NIV by means of a helmet immediately after extubation in all cases; therefore, the authors cannot assert if this procedure is strictly necessary. Despite this, we recommend the use of continuous positive airway pressure given that no mortality occurred in the recovery after PNCT [23-25].

The follow up has several crucial points. Most importantly, we found the early detection of health impairment to be the pivotal factor. In fact, swine easily surrender in the case of disease, especially after considerable trauma such as major surgery. A superficial attitude of caregivers and hasty observation could lead to the loss of a model entailing several drawbacks (animal suffering, economy, and research nullification). We thus evolved a method of care-taking intended to prevent the complication worsening with intensive supportive care when the complication is still a hypothesis. The possible impact of postoperative complications could have consequences on the surgical laboratory. To lose $10 \%$ of models after no postoperative cure represents $20 \%$ of the total budget, which could rise to $40 \%$ if a model is lost after application of therapeutic materials.

The routine required three scrubbed investigators and one anesthesiologist. Circulators are necessary and depend on research protocols. Moreover, the data suggest that after the perioperative period, the afternoon round can be avoided but we do not follow this routine scheme. 


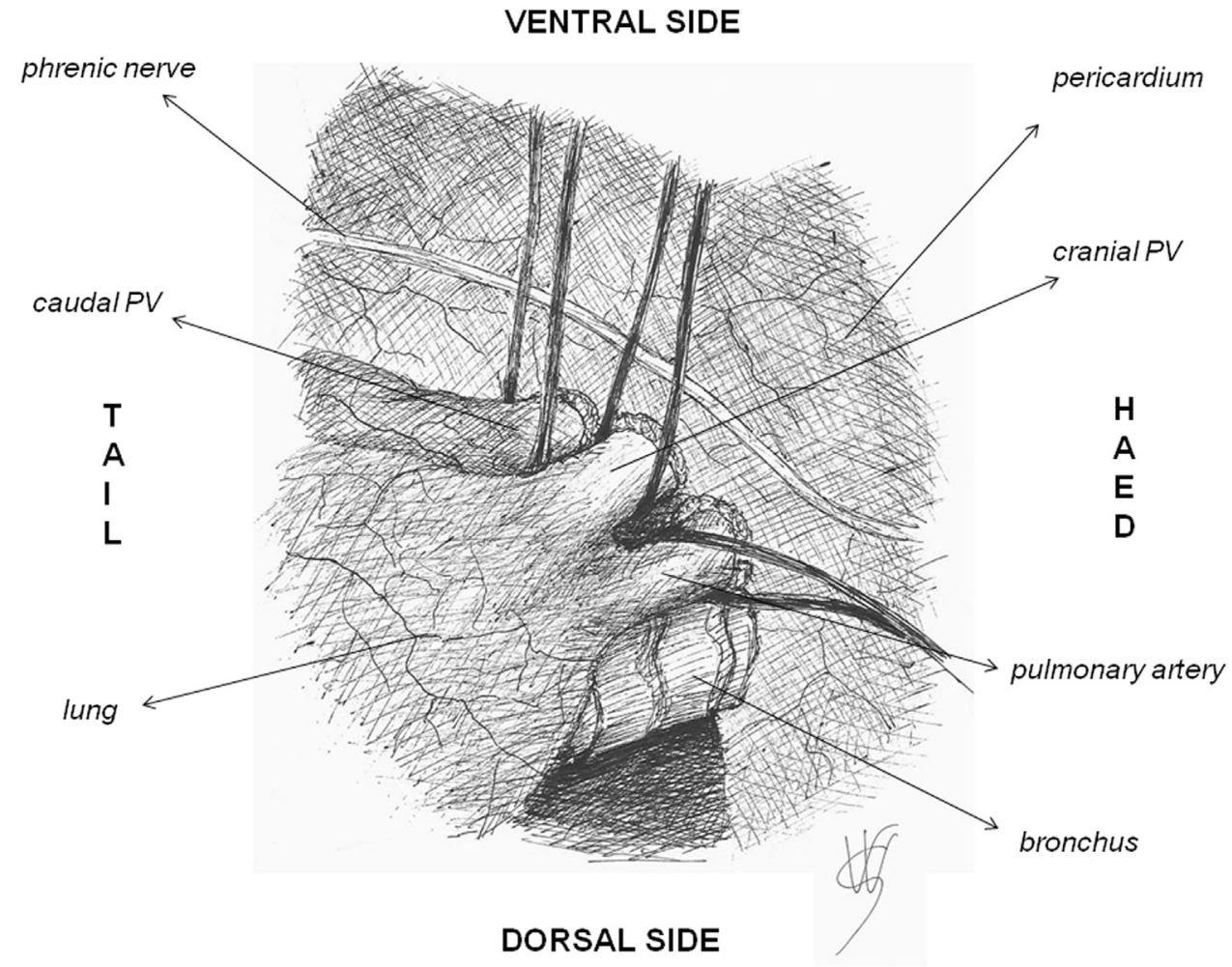

Fig. 6 - All the bronchovascular elements are shown, held on vessel loop; illustration of surgical anatomy just before PNCT is carried out.

\section{Acknowledgment}

The authors thank Walter Santilli R.N. for the artworks.

The study was supported by a Research Grant from Fondazione Cassa di Risparmio di Perugia (Grant number 2010.011.0431), Perugia, Italy.

Authors' contribution: A.B., J.V., V.D.M., and R.P. designed the study, wrote the article, and analyzed the operative experience. L.D. performed the data records and follow-up. S.C., L.C., and M.R. substantially contributed to each part (operative and investigational) of the study development.

\section{Disclosure}

The authors have no conflict of interest.

\section{Supplementary data}

Supplementary data related to this article can be found at http://dx.doi.org/10.1016/j.jss.2015.05.045.

\section{R E F E R E N C E S}

[1] Puma F, Avenia N, Ricci F, et al. Bone heterograft for chest wall reconstruction after sternal resection. Ann Thorac Surg 1996;61:525.
[2] Puma F, Farabi R, Urbani M, et al. Long-term safety and tolerance of silicone and self-expandable airway stents: an experimental study. Ann Thorac Surg 2000;69:1030.

[3] Swindle M. Swine in the laboratory. 2nd ed. Boca Raton, FL: Taylor and Francis Group; 2007.

[4] Karimi A, Cobb JA, Staples ED, et al. Technical pearls for swine lung transplantation. J Surg Res 2011;171:e107.

[5] Staffieri F, Crovace A, De Monte V, et al. Noninvasive continuous positive airway pressure delivered using a pediatric helmet in dogs recovering from general anesthesia. J Vet Emerg Crit Care (san Antonio) 2014;24:578.

[6] Sage E, Mercier O, Herve P, et al. Right lung ischemia induces contralateral pulmonary vasculopathy in an animal model. J Thorac Cardiovasc Surg 2012;143:967.

[7] Lan CC, Hsu HH, Wu CP, et al. Lateral position with the remaining lung uppermost improves matching of pulmonary ventilation and perfusion in pneumonectomized pigs. J Surg Res 2011;167:e55.

[8] Lan CC, Chang CY, Peng CK, et al. Effect of body positions on hemodynamics and gas exchange in anesthetized pigs shortly after pneumonectomy. Shock 2010;34:482.

[9] Opitz I, Erne BV, Demirbas S, et al. Optimized intrapleural cisplatin chemotherapy with a fibrin carrier after extrapleural pneumonectomy: a preclinical study. J Thorac Cardiovasc Surg 2011;141:65.

[10] Berthet JP, Attard O, Solovei L, et al. Delayed pulmonary arterial hypertension in relation to pulmonary damage score after pneumonectomy under protective ventilation: experimental study. Eur Surg Res 2013;51:170.

[11] Getman V, Devyatko E, Abraham D, et al. Reconstitution of blood supply of the denuded bronchial stump. Ann Thorac Surg 2005;80:2063.

[12] Iglesias M, Jungebluth P, Petit C, et al. Extracorporeal lung membrane provides better lung protection than 
conventional treatment for severe postpneumonectomy noncardiogenic acute respiratory distress syndrome. J Thorac Cardiovasc Surg 2008;135:1362.

[13] Roch A, Michelet P, D'journo B, et al. Accuracy and limits of transpulmonary dilution methods in estimating extravascular lung water after pneumonectomy. Chest 2005; 128:927.

[14] Swindle MM, Makin A, Herron AJ, Clubb FJ Jr, Frazier KS. Swine as models in biomedical research and toxicology testing. Vet Pathol 2012;49:344.

[15] Daddi N, Vannucci J, Maggio C, et al. Efficacy of tigecycline pleurodesis: a comparative experimental study. J Surg Res 2011;169:e109.

[16] Hughes HC. Swine in cardiovascular research. Lab Anim Sci 1986;36:348.

[17] De Robertis E, Liu JM, Blomquist S, et al. Elastic properties of the lung and the chest wall in young and adult healthy pigs. Eur Respir J 2001;17:703.

[18] Thurmon JC, Tranquilli WJ, Benson GJ. Preanesthetics and anesthetic adjuncts. In: Thurmon JC, Tranquilli WJ, Benson GJ, editors. Lumb \& Jones Veterinary Anesthesia. 3rd ed. Baltimore: Williams and Wilkins; 1996. p. 183-209.
[19] Hall LW, Clarke KW, Trim CM. Principles of sedation, analgesia and premedication. In: Hall LW, Clarke KW, Trim CM, editors. Veterinary Anaesthesia. 10th ed. London: W.B. Saunders; 2001. p. 75-112.

[20] Bauquier SH, Culp WT, Lin RC, Larenza MP. One-lung ventilation using a wire-guided endobronchial blocker for thoracoscopic pericardial fenestration in a dog. Can Vet J 2010;51:1135.

[21] Theroux MC, Fisher AO, Horner LM, et al. Protective ventilation to reduce inflammatory injury from one lung ventilation in a piglet model. Paediatr Anaesth 2010;20:356.

[22] Garutti I, Rancan L, Simón C, et al. Intravenous lidocaine decreases tumor necrosis factor alpha expression both locally and systemically in pigs undergoing lung resection surgery. Anesth Analg 2014;119:815.

[23] Chiumello D, Coppola S. Does prophylactic CPAP have any role in thoracic surgery? Respir Care 2012;57:474.

[24] Jaber S, De Jong A, Castagnoli A, et al. Non-invasive ventilation after surgery. Ann Fr Anesth Reanim 2014;33:487.

[25] Koutsogiannidis CP, Ampatzidou FC, Ananiadou OG, et al. Noninvasive ventilation for post-pneumonectomy severe hypoxemia. Respir Care 2012;57:1514. 